\title{
Characterization of the A6060 Al Alloy Mainly by Using the Micro-Hardness Vickers Test in Order to Optimize the Industrial Solutionizing Conditions of the As-Cast Billets
}

\author{
G. K. Triantafyllidis, I. Kiligaridis, D. I. Zagkliveris, I. Orfanou, S. Spyridopoulou, \\ E. Mitoudi-Vagourdi, S. Semertzidou \\ Department of Chemical Engineering, Aristotle University, Thessaloniki, Greece \\ Email: gktrian@auth.gr
}

Received 28 December 2014; accepted 16 January 2015; published 21 January 2015

Copyright (C) 2015 by authors and Scientific Research Publishing Inc.

This work is licensed under the Creative Commons Attribution International License (CC BY).

http://creativecommons.org/licenses/by/4.0/

cc) (i)

\begin{abstract}
Heat treatable $\mathrm{Al}$ alloys of the $6 \mathrm{xxx}$ series are produced by the industry following a path that consolidates melting of raw materials, casting the melt in billets, solutionizing the billets following a suitable thermal cycle, pre-heating and extruding the material to profiles and finally aging the profiles. Although this procedure is known for pure materials from the scientific point of view, the introduction of scrap to the raw materials for melting modifies to an extent the fabrication conditions that follow casting. This fact affects the production cost. In this article we propose a research way based mainly on micro-Vickers tests that lead to an optimization of the treatment conditions for solutionizing the billets.
\end{abstract}

\section{Keywords}

A6060 Al Alloy, Strengthening, Solutionizing, Aging, Micro-Vickers

\section{Introduction}

Aluminum alloys are being widely used for structural components in industry because of their light weight, strength, and formability. Pure aluminum is too soft for structural components. Alloying it with other elements increases its strength. The increase in strength is achieved either through solid solution or precipitation harden- 
ing. Precipitation hardening occurs during aging after the solutionizing treatment. Alloying elements in supersaturated solution form precipitates. Adding Mg, Si to aluminum constitutes the heat-treatable 6xxx series aluminum alloys. Commercial 6xxx alloys are either balanced in $\mathrm{Mg}$ - and Si-content to form quasi-binary Al$\mathrm{Mg}_{2} \mathrm{Si}$ alloys, or they have excess Si or Mg above the concentration needed to form $\mathrm{Mg}_{2} \mathrm{Si}$. Balanced alloys are normally press-quenched, thereby eliminating the need to solution treatment before aging. However, alloys with excess Si or Mg are more sensitive to the quenching conditions and therefore it is usually necessary to solutionize them before aging [1] [2].

The production cost of the profiles of the A6060 alloy (the simplest alloy of the series named above) is an important parameter for the industry. Scrap is added to the melt for economical reasons. Thermal treatment conditions so (in this case mainly the temperature and soaking time of the solutionizing treatment), should be optimized for better economical results. This could be done by following a reliable R\&D program as proposed in the article. The program is based on the fact that Al grains are progressively strengthened by dispersoids, as theory suggests, and this could be determined by Vickers micro-hardness tests.

\section{Theoretical Background for Solutionizing and Aging}

Both chemistry and processing conditions will influence the microstructure of aluminum alloys of the type A6060 (constituent particles, dispersoids, amounts of elements in solid solution, age-hardening precipitates, grain size, and texture).

The solid solution level of Mg and Si before aging depends primarily on the amount of non-hardening Mg and Si-containing precipitates in the material, in particular $\beta^{\prime}-\mathrm{Mg}_{1.8} \mathrm{Si}$ rods, which should be as low as possible to achieve high strength. In addition, the amount of Si tied up in constituent Fe-rich phases formed during solidification and homogenization also influences the solid solution level of Si. The amount of Mg-Si precipitates depends on several processing parameters:

- The homogenization temperature and time: Some Si is trapped in Fe-containing constituent phases like $\alpha$ AlFeSi and $\beta$-AlFeSi, and in $\alpha$-AlFeSi dispersoids formed during homogenization. The $\alpha$-AlFeSi dispersoids act as nucleation sites for $\beta$-Mg ${ }_{1.8} \mathrm{Si}$. The amount of Fe-containing constituent particles and the size, density and distribution of $\alpha$-AlFeSi dispersoids are a function of alloy composition, homogenization temperature and homogenization time.

- The cooling rate after homogenization: $\beta^{\prime}-\mathrm{Mg}_{1.8} \mathrm{Si}$ in the extruded sections form in general during cooling from elevated temperatures. A low cooling rate favors the precipitation of the $\beta^{\prime}$-phase, most of which will dissolve during preheating of the extrusion billet.

- The preheating temperature and time during extrusion: coarse $\beta^{\prime}$-particles may survive the preheating and extrusion process and thus reduce the solid solution level after extrusion. If the preheating is done at too low temperature and the time is too short, the $\beta^{\prime}$-precipitates may not fully dissolve, and thus the age hardening potential is lowered.

- The cooling rate after extrusion: As with homogenization, a low cooling rate after extrusion leads to increased amount of $\beta^{\prime}$-particles.

As mentioned above, some of the Si will be tied up in the Fe-rich phases during the casting and homogenization processes. Consequently, the temperature-time cycles of these up-stream processes will affect the Si-content available for precipitation of Mg-Si-precipitates in the final processing step of extrusions and thus have an important impact on the mechanical properties of the end product [2].

The main strength provider in Al-Mg-Si alloys is the coherent Mg-Si precipitates. The atomic structure of Mg-Si-precipitates depends on the age hardening cycle, in terms of temperature and time, and the amount of Mg and $\mathrm{Si}$ in solid solution in the aluminum matrix available to form the precipitates. In accordance with state of the art understanding of the precipitation behavior in these alloys, Andersen et al. [3] have described the precipitation sequence as:

$\mathrm{SSSS} \rightarrow$ atomic clusters $\rightarrow$ GP-zones $\rightarrow \beta^{\prime \prime} \rightarrow \beta^{\prime}, \mathrm{U} 1, \mathrm{U} 2, \mathrm{~B}^{\prime} \rightarrow \beta$, Si

(SSSS, Super Saturated Solid Solution; $\beta^{\prime \prime}, \mathrm{Mg}_{5} \mathrm{Si}_{6} ; \beta^{\prime}, \mathrm{Mg}_{1.8} \mathrm{Si} ; \mathrm{U1}, \mathrm{MgAl}_{2} \mathrm{Si}_{2} ; \mathrm{U} 2, \mathrm{MgAlSi} ; \mathrm{B}^{\prime}, \mathrm{Mg}_{9} \mathrm{Al}_{3} \mathrm{Si}_{7} ; \beta$, $\mathrm{Mg}_{2} \mathrm{Si}$ ). The SSSS-level of $\mathrm{Mg}$ and $\mathrm{Si}$ depends on the chemical composition of the alloy as well as the thermomechanical history of the material in the process stages prior to age hardening. This will influence how much $\mathrm{Mg}$ and Si is captured in constituent particles or other non age-hardening precipitates. In conclusion:

- $\quad \beta^{\prime \prime}$ (beta double prime) $\mathrm{Mg}_{5} \mathrm{Si}_{6}$, the smallest type of $\mathrm{Mg}-\mathrm{Si}$ precipitate that is rod-shaped and contributes most 
to mechanical properties when densely dispersed.

- $\quad \beta^{\prime}$ (beta prime) $\mathrm{Mg}_{1.8} \mathrm{Si}$, a larger version of rod-shaped precipitate that grows from the $\beta^{\prime \prime}$ category. The $\beta^{\prime}$ precipitates have a negligible contribution to mechanical properties.

- $\quad \beta$ (beta) $\mathrm{Mg}_{2} \mathrm{Si}$, the largest Mg-Si precipitate that is cube-like in shape and due to its size contributes nothing to mechanical properties.

Iron $(\mathrm{Fe})$ is also present in the alloys and combines with silicon (Si) and aluminum (Al) to form AlFeSi intermetallics. These intermetallics do not contribute to the strength of the alloy but, if they are not correctly processed, they will have a detrimental effect on the extrudability of the alloy.

The Mg-Si dispersoids must dissolve into solution during extrusion as the deforming material passes through the deformation zone. A fine and uniform distribution of Mg-Si can be obtained by good casting process, homogenization and rapid reheating to the extrusion temperature [4].

This discussion declares out that in estimating the level of strengthening of the alloy during the solutionizing heat treatment before extrusion, the Al matrix grains could be considered independently. Alloying elements and the Mg-Si dispersoids diffuse inside them resulting in solid solution strengthening. This type of strengthening can be measured and characterized by Vickers micro-hardness tests of the Al matrix grains.

\section{Experimental Procedure}

Alumil SA follows a production way for profiles of the A6060 alloy based on suggestions from free consultants:

- Melting pure aluminum ingots and aluminum scrap and chemically adjusting the melt by proper additions of $\mathrm{Si}, \mathrm{Mg}$, Ti. Control of the chemical composition of the melt (Table 1) by OES measurements.

- Casting the melt in a vertical direct chill casting machine in billets 6 meters in length and with diameters of 152, 178 and/or $203 \mathrm{~mm}$.

- Solutionizing of the billets at $620^{\circ} \mathrm{C}$ (air temperature inside the furnace) $/ 585^{\circ} \mathrm{C}$ (temperature of the metal surface) for 10 hrs (4.5 hours ramp to soak temperature and 5.5 hours effective holding time).

- Quenching at ambient temperature by an air fan.

- Preheating and extrusion pressing of the billets (at $480^{\circ} \mathrm{C}$, exit at $540^{\circ} \mathrm{C}$ ) to properly designed profiles.

- Cooling under air hood.

- Precipitation hardening at $180^{\circ} \mathrm{C}$ for $7 \mathrm{hrs}$, which is followed by cooling in the atmosphere.

Industry needs fast and economical ways to characterize the material within each one of the production steps with the aim to decrease the cost of products with acceptable properties (in this case according to EN 755-2 for T6, minimum mechanical properties for architectural profiles: $R_{m}: 190 \mathrm{MPa}, R_{p} 0.2: 150 \mathrm{MPa}$, A: 6\%, HB: 65).

As far as this production program is concerned we noticed a high solution temperature and long holding time in relation to the $530^{\circ} \mathrm{C}$, as given in the literature for most of the $6 \mathrm{xxx}$ family of $\mathrm{Al}$ alloys [5].

We proposed, so, an R\&D program for monitoring the industrial solutionizing conditions towards lower soak temperatures and shorter holding times. Holding temperatures and times for laboratory sized samples were adjusted according to [6].

Table 2 presents the results of micro-VHN measurements at each stage of the production process, as described above, and, additionally, the micro-VHN measurements of samples solutionized as described, but aged in other conditions for comparative purposes.

\subsection{The Research Program}

Slices of $15 \mathrm{~mm}$ in width (for practical laboratory reasons) normal to the cylinder axis of the as-cast billet were cut out under cooling water at ambient temperature (cold cutting). Cubic samples with a $=15 \mathrm{~mm}$ were prepared out from these slices and subjected to solutionizing with the following characteristics:

- Holding temperature from $530^{\circ} \mathrm{C}$ to $620^{\circ} \mathrm{C}$ in steps of $10^{\circ} \mathrm{C}$.

- Heating ramp to achieve the temperature set point $40^{\circ} \mathrm{C} / \mathrm{min}$.

- Holding (soak) times 80 and 70 min ([5] page 296).

- Quenching in liquid nitrogen, running water at ambient temperature and air fan at ambient temperature.

This program was expanded from $530^{\circ} \mathrm{C}$ down to $480^{\circ} \mathrm{C}$ in steps of $10^{\circ} \mathrm{C}$ and quenched only by air fan at ambient temperature.

In the following, samples in the form of cubes $(\mathrm{a}=15 \mathrm{~mm})$ will be referred simply as "cubes". Samples from extruded products have dimensions $15 \times 15 \times 1.5 \mathrm{~mm}$ and will be referred as "plates". 
Table 1. Chemical composition of the A6060 aluminum alloy.

\begin{tabular}{ccccccccc}
\hline \multirow{2}{*}{ Alloy } & \multicolumn{8}{c}{ Alloy elements } \\
\cline { 2 - 9 } & $\mathrm{Si}$ & $\mathrm{Fe}$ & $\mathrm{Cu}$ & $\mathrm{Mn}$ & $\mathrm{Mg}$ & $\mathrm{Cr}$ & $\mathrm{Zn}$ & $\mathrm{Ti}$ \\
\hline $\mathrm{A} 6060$ & 0.44 & 0.33 & 0.029 & 0.039 & 0.43 & 0.0095 & 0.053 & 0.016 \\
\hline
\end{tabular}

Table 2. Average micro-hardness values for various alloy conditions (the value corresponding to the industrial aging conditions is underlined).

\begin{tabular}{|c|c|c|c|c|}
\hline Alloy condition & \multicolumn{4}{|c|}{ Micro-hardness (VHN) } \\
\hline Pure Al & \multicolumn{4}{|c|}{25} \\
\hline Cubes A6060 as-cast & \multicolumn{4}{|c|}{39} \\
\hline \multirow[t]{3}{*}{ Plates A6060 as-extruded } & & \multicolumn{2}{|c|}{54} & \\
\hline & & $175^{\circ} \mathrm{C}$ & $180^{\circ} \mathrm{C}$ & $185^{\circ} \mathrm{C}$ \\
\hline & 6 hrs & 62 & 71 & 75 \\
\hline \multirow[t]{2}{*}{$\begin{array}{l}\text { Cubes A6060 solutionized at } 620^{\circ} \mathrm{C} \\
\text { for } 80 \mathrm{~min} \text { and aged for }\end{array}$} & 7 hrs & 71 & $\underline{74}$ & 79 \\
\hline & 8 hrs & 76 & 77 & 84 \\
\hline
\end{tabular}

Optical metallography revealed a structure as depicted in Figure $1(200 \times)$. Measurement of the strengthening level of the Al grains was performed by Vickers micro-hardness tests (AFFRI Instrument, $100 \mathrm{gf}$ ) on the surfaces of the cubes which were suitably prepared for metallographic examination (grinding, polishing, etching in Keller's reagent). For good statistics 15 measurements were performed on each surface. The results of this work are presented in Figure 2.

Micro-hardness VHN values for the existing products of the factory (aging cycle) are given in Figure 3 (the samples were cut out from commercial profiles made out of alloy A6060).

\subsection{The Development Program}

By taking into consideration the results, thermal cycles in the factory for the solution treatment at $540^{\circ} \mathrm{C}$ for 3.5 and 5.5 hrs holding time had been suggested. Industrial heating ramp remains at 4.5 hrs to achieve the soaking temperature. The holding times for the billets were calculated in relation to the width of the specimen (a scaling up from the a $=15 \mathrm{~mm}$ for the laboratory cubes to $\varnothing 203 \mathrm{~mm}$ diameter of the as-cast billets).

The factory produced profiles following this proposal: melting, casting in billets, solutionizing at temperature and holding time as proposed, extrusion-production of final profiles as for the normal products. Plates from the profiles were subjected to aging at $175^{\circ} \mathrm{C}, 180^{\circ} \mathrm{C}$ and $185^{\circ} \mathrm{C}$ for 6,7 and $8 \mathrm{hrs}$. The VHN measurements for each condition are presented in Table 3 (3.5 hrs holding time) and Table 4 (5.5 hrs holding time) and the HRF in Table 5 (3.5 hrs) and Table 6 (5.5 hrs).

The four most efficient cycles (named as (1), (2), (3) and (4) in Tables 3-6) were selected for aging at a laboratory scale (200 $\mathrm{mm}$ long profile pieces). Specimens from these profile pieces were subjected to tensile testing with the results given in Table 7. The stress-strain diagrams of the selected cycles are presented in Figures 4-7.

Industry, then, follows these financially improved conditions for the production of profiles. The scope of this program is to provide aluminum casting and extrusion industry with the guidelines for a more effective and economic management of the homogenization process.

The effect of the outcome of the program's implementation on other significant parameters such as productivity and cost (e.g. extrusion speed, die wear-out etc.) must be assessed in order to confirm its validity.

\section{Discussion}

$\mathrm{Al}$ matrix grains of the as-cast and the solutionized material (Figure 1) exposed a broad area sufficient enough to accept the surface of the 100 gf identation of the micro-Vickers test. The results, so, in treating the alloy as an Al-MMC are considered as reliable. 


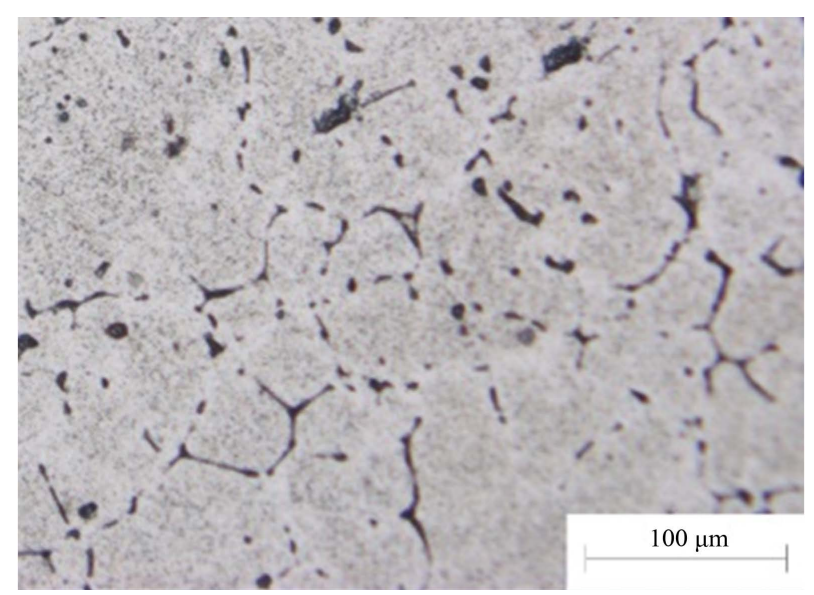

Figure 1. Microstructure of an Al-Mg-Si as-cast alloy (200×).

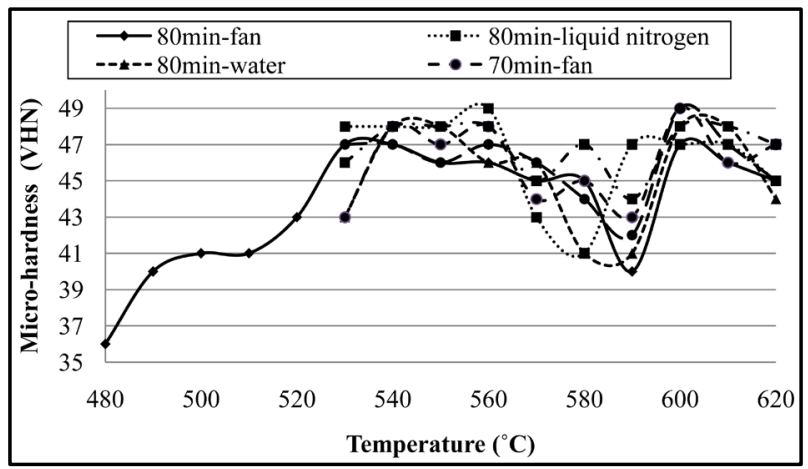

Figure 2. Micro-Vickers (VHN) values of solutionized samples at various temperatures.

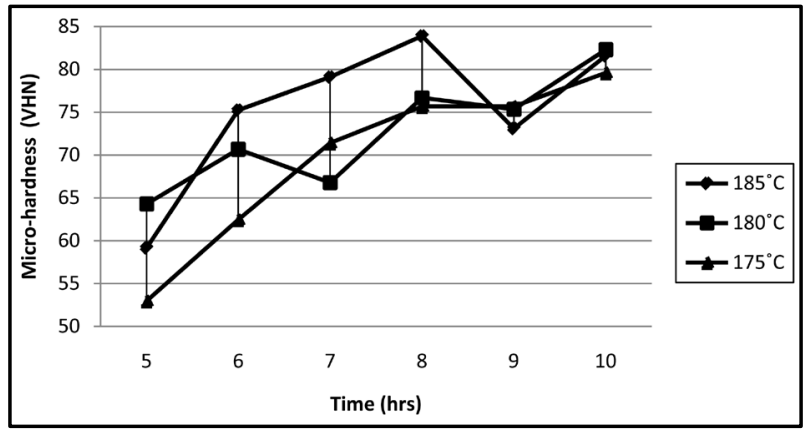

Figure 3. Micro-hardness of solutionized (at $620^{\circ} \mathrm{C}$ for $80 \mathrm{~min}$ ) and extruded samples, aged for various times.

- A high heating ramp $\left(40^{\circ} \mathrm{C} / \mathrm{min}\right)$ was applied in the research to achieve the soaking temperature in order to characterize better the solutionizing process.

- Industrial heating ramp of the factory considered as non changeable.

- Results as presented in Figure 2 suggest that there are two broad solutionizing temperature ranges $\left(530^{\circ} \mathrm{C}\right.$ to $560^{\circ} \mathrm{C}$ and above $580^{\circ} \mathrm{C}$ up to $620^{\circ} \mathrm{C}$, with a gap between $560^{\circ} \mathrm{C}$ and $580^{\circ} \mathrm{C}$ ) for which the strengthening result of the solution treatment expressed in VHN inside the $\mathrm{Al}$ grains is comparable in absolute values. The factory applies the $>580^{\circ} \mathrm{C}$ range. The lower range fits to the bibliographical data of [5].

- Intense quenching conditions after solutionizing (liquid nitrogen, running water at room temperature versus air fan) seem to have not considerable influence on the VHN of the solutionized products. They do not alter 
Table 3. Micro-hardness values of extruded and aged samples (3.5 hrs solutionizing holding time).

\begin{tabular}{cccc}
\hline \multirow{2}{*}{ Aging temperature } & \multicolumn{3}{c}{ Holding time } \\
\cline { 2 - 4 } & $6 \mathrm{hrs}$ & $7 \mathrm{hrs}$ & $8 \mathrm{hrs}$ \\
\hline $\mathbf{1 7 5}^{\circ} \mathbf{C}$ & 68.8 & 68.6 & 74.5 \\
$\mathbf{1 8 0}^{\circ} \mathbf{C}$ & 63.8 & 71.5 & $\underline{\mathbf{7 8 . 0}}(1)$ \\
$\mathbf{1 8 5}^{\circ} \mathbf{C}$ & 70.3 & $\underline{\mathbf{7 6 . 6}}(2)$ & 77.8 \\
\hline
\end{tabular}

Table 4. Micro-hardness values of extruded and aged samples (5.5 hrs solutionizing holding time).

\begin{tabular}{cccc}
\hline \multirow{2}{*}{ Aging temperature } & \multicolumn{3}{c}{ Holding time } \\
\cline { 2 - 4 } & $6 \mathrm{hrs}$ & $7 \mathrm{hrs}$ & $8 \mathrm{hrs}$ \\
\hline $\mathbf{1 7 5}^{\circ} \mathrm{C}$ & 61.4 & 68.7 & 71.1 \\
$\mathbf{1 8 0}^{\circ} \mathrm{C}$ & 63.3 & 71.2 & $\underline{\mathbf{7 6 . 3}}(3)$ \\
$\mathbf{1 8 5}^{\circ} \mathbf{C}$ & 67.7 & $\underline{\mathbf{7 6 . 2}}(4)$ & 74.2 \\
\hline
\end{tabular}

Table 5. Hardness Rockwell-F values of extruded and aged samples (3.5 hrs solutionizing holding time).

\begin{tabular}{cccc}
\hline \multirow{2}{*}{ Aging temperature } & \multicolumn{3}{c}{ Holding time } \\
\cline { 2 - 4 } & $6 \mathrm{hrs}$ & $7 \mathrm{hrs}$ & $8 \mathrm{hrs}$ \\
\hline $\mathbf{1 7 5}^{\circ} \mathbf{C}$ & 33.2 & 42.0 & 51.0 \\
$\mathbf{1 8 0}^{\circ} \mathbf{C}$ & 38.6 & 51.1 & $\underline{\mathbf{5 5 . 0}}(1)$ \\
$\mathbf{1 8 5}^{\circ} \mathbf{C}$ & 42.8 & $\underline{\mathbf{5 3 . 1}}(2)$ & 51.2 \\
\hline
\end{tabular}

Table 6. Hardness Rockwell-F values of extruded and aged samples (5.5 hrs solutionizing holding time).

\begin{tabular}{cccc}
\hline \multirow{2}{*}{ Aging temperature } & \multicolumn{3}{c}{ Holding time } \\
\cline { 2 - 4 } & 6 hrs & 7 hrs & 8 hrs \\
\hline $\mathbf{1 7 5}^{\circ} \mathbf{C}$ & 34.1 & 48.0 & 50.2 \\
$\mathbf{1 8 0}^{\circ} \mathbf{C}$ & 37.8 & 51.1 & $\underline{\mathbf{6 1 . 6}}(3)$ \\
$\mathbf{1 8 5}^{\circ} \mathbf{C}$ & 48.0 & $\underline{\mathbf{5 6 . 9}}(4)$ & 58.8 \\
\hline
\end{tabular}

Table 7. Tensile test results for the profiles of the selected heat treatment cycles.

\begin{tabular}{ccccc}
\hline \multirow{2}{*}{$\begin{array}{c}\text { Heat treatment } \\
\text { cycle }\end{array}$} & \multicolumn{4}{c}{ Mechanical properties } \\
\cline { 2 - 5 } $\mathbf{1}$ & 13.0 & $R_{m}(\mathrm{MPa})$ & $R_{p}(\mathrm{MPa})$ & $\mathrm{A} 5(\%)$ \\
$\mathbf{2}$ & 13.0 & 227 & 188 & 12.67 \\
$\mathbf{3}$ & 13.0 & 229 & 191 & 12.69 \\
$\mathbf{4}$ & 12.5 & 217 & 168 & 13.60 \\
& & 220 & 179 & 12.36 \\
\hline
\end{tabular}




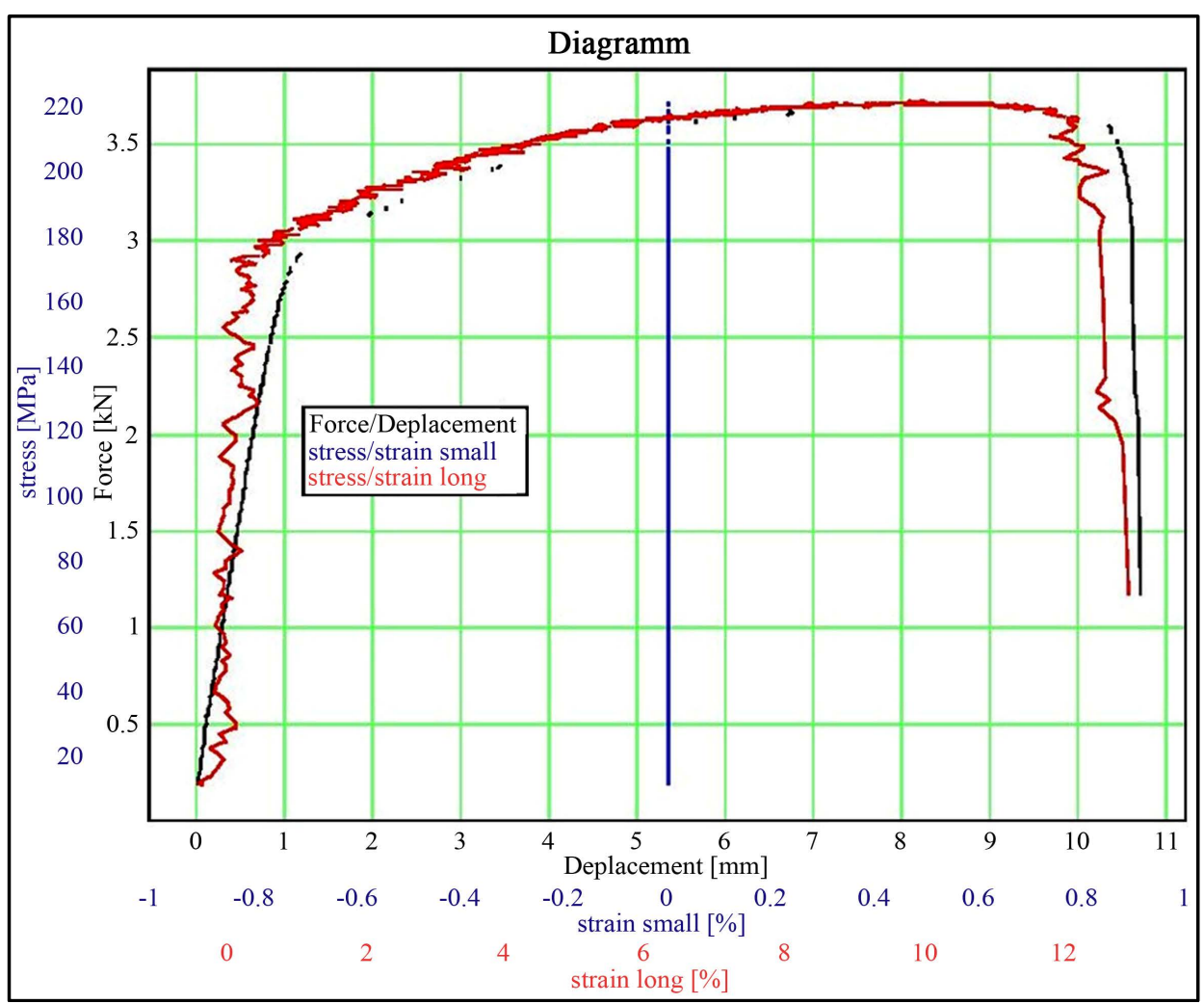

Figure 4. Tensile test of the extruded and aged sample (1) $(\mathrm{VHN}=78.0)$.

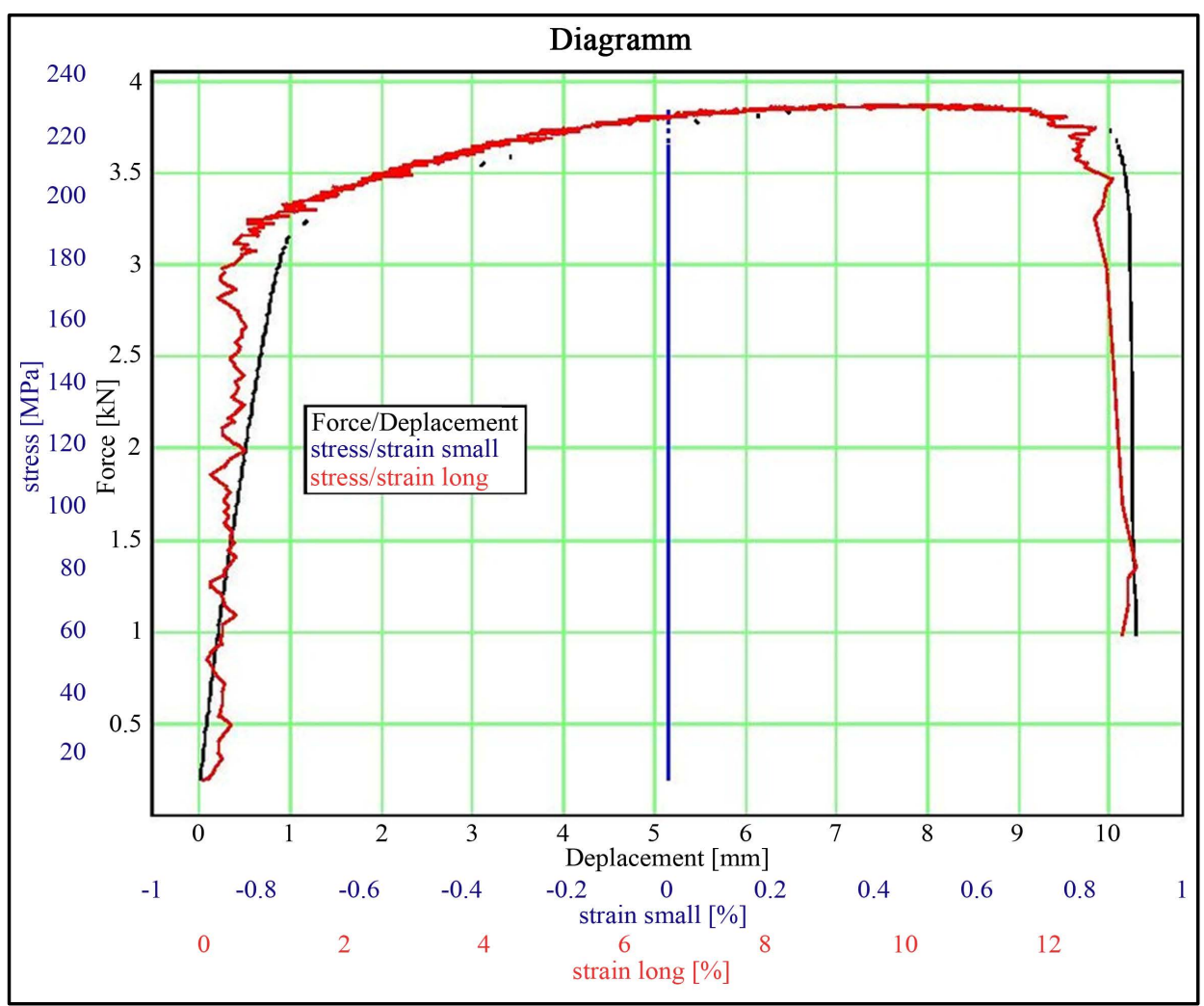

Figure 5. Tensile test of the extruded and aged sample $(2)(\mathrm{VHN}=76.6)$. 


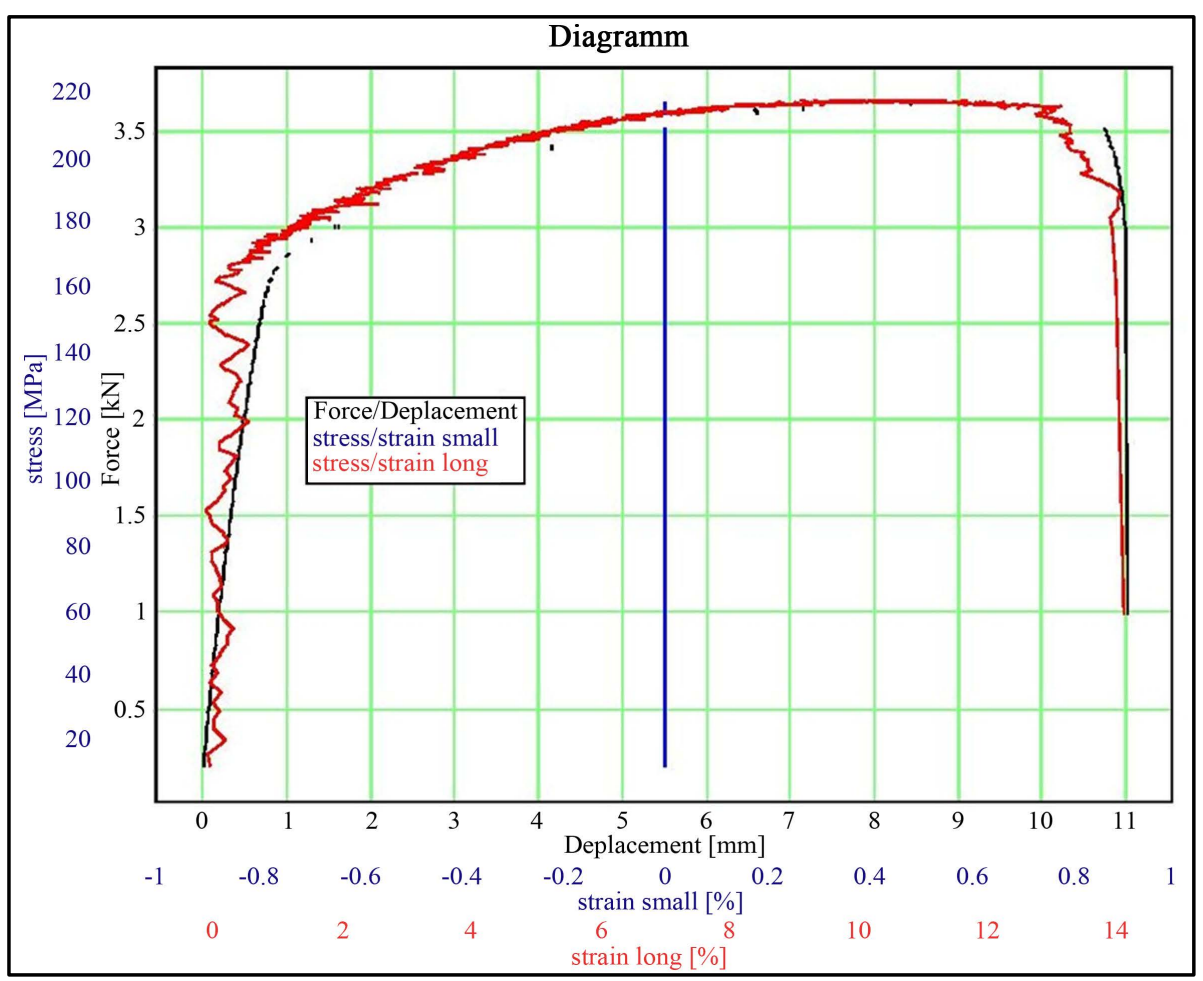

Figure 6. Tensile test of the extruded and aged sample (3) $(\mathrm{VHN}=76.3)$.

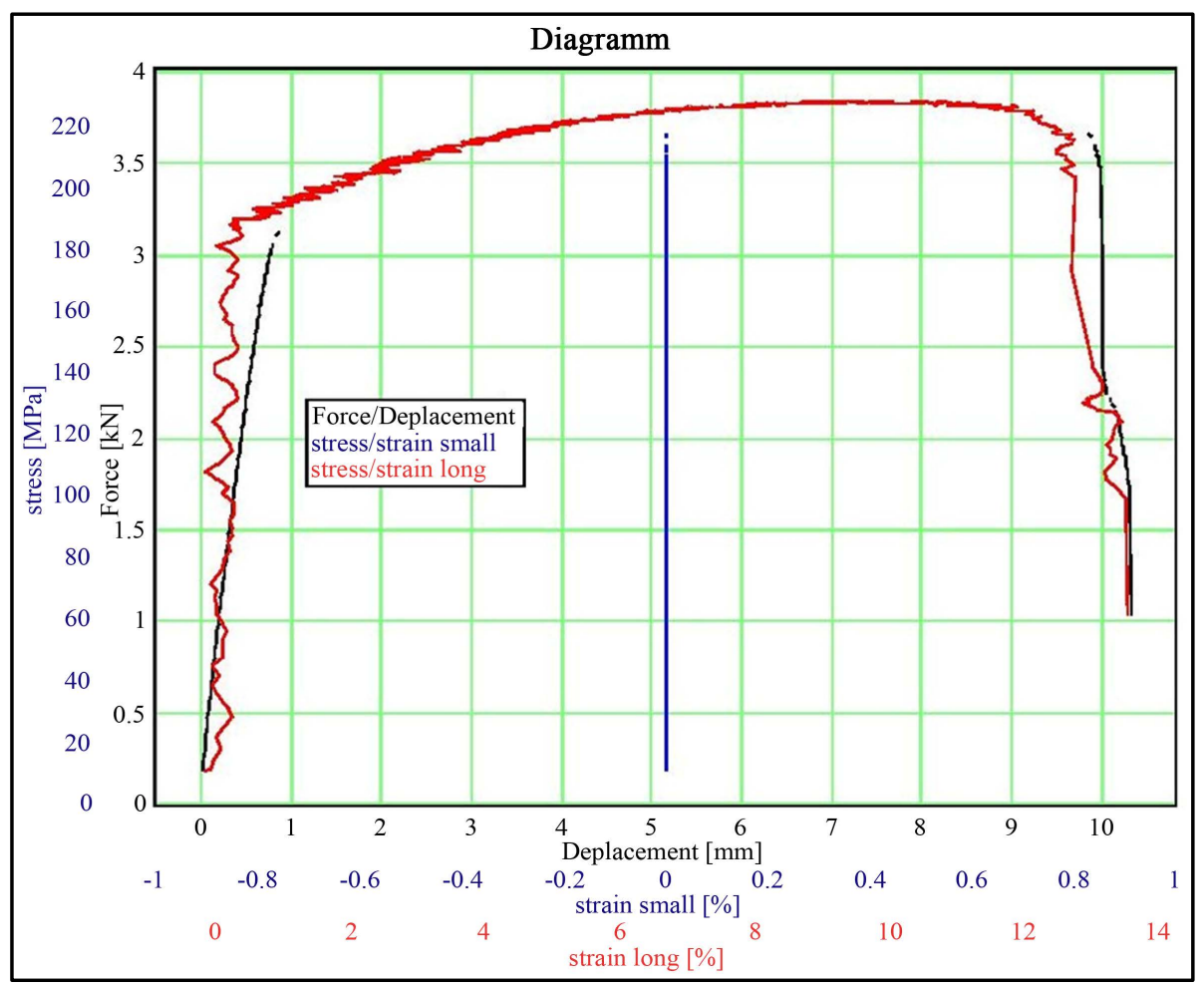

Figure 7. Tensile test of the extruded and aged sample (4) $(\mathrm{VHN}=76.2)$.

the type of the curves.

- This strengthening is considerably enhanced by the extrusion process that follows and is the basis for the ag- 
ing treatment.

- In Table 2 the progressive increase in the strengthening level from the pure Al metal-to the as-cast A6060 alloy - to the solutionized and aged (but not extruded) alloy and to the as-extruded (but not aged) alloy is indicated.

- Micrograph of the extruded and aged material does not present grains with clear boundaries. Thus HRF measurement was applied in order to determine the strengthening result of the extrusion process.

- Hardness tests of the macro-scale (Brinell-Webster) treat the material as a whole and are not so sensitive to characterize the strengthening progress as described above. HRF as a macro-hardness test was applied on the aged material only.

\section{Conclusions}

The A6060 alloy in the as-cast condition was treated in this article as an Al-MMC with the Al (rich) grains being the matrix material (Figure 1). Mg-Si dispersoids strengthen the Al matrix grains during the solutionizing heat treatment, the subsequent extrusion and aging. The level of strengthening was followed up and measured by Vickers micro-hardness tests with 100 gf. The type of curves of Figure 2 is very characteristic in choosing the soak temperature of the solutionizing treatment. The theoretical background of the process has been presented but micro-VHN of the Al grains only is insufficient to indicate the type of dispersoids that control any strengthening effect.

Micro-Vickers hardness was also used to characterize the material after the aging cycle in conjunction to macro-hardness tests (Rockwell $\mathrm{F}$ in this case).

The proposed development program, based on the results of the research as described, had success as far as the mechanical properties of the final profiles is concerned. As a production route is now used by the industry.

Although it is a rough approximation to what happens at an atomic scale in the grains (as clearly is referred in the text following the bibliographical data), micro-hardness Vickers test results of the Al grains seem to be very realistic in estimating the strengthening level during the solutionizing heat treatment and monitoring its thermal cycle.

\section{Acknowledgements}

We are grateful for the technical and financial support of the Al profiles producing company ALUMIL SA.

\section{References}

[1] Hatch, E.J. (1999) Aluminum: Properties and Physical Metallurgy. 9th Printing, American Society for Metals.

[2] Bahrami, A. (2010) Modeling of Precipitation Sequence and Aging Kinetics in Al-Mg-Si Alloy. Sharif University of Technology, Tehran.

[3] Fjeldbo, S.K., Li, Y.J., Marthinsen, K. and Furu, T. (2012) Through-Process Sensitivity Analysis on the Effect of Process Variables on Strength in Extruded Al-Mg-Si Alloys. Journal of Materials Processing Technology, 212, 171-180. http://dx.doi.org/10.1016/j.jmatprotec.2011.08.020

[4] Andersen, S.J., Marioara, C.D., Vissers, R., Froeseth, A. and Zandbergen, H.W. (2007) The Structural Relation between Precipitates in Al-Mg-Si Alloys, the Al-Matrix and Diamond Silicon, with Emphasis on the Trigonal Phase U1-MgAl ${ }_{2} \mathrm{Si}_{2}$. Materials Science and Engineering, A444, 157-169. http://dx.doi.org/10.1016/j.msea.2006.08.084

[5] Sheppard, T. (1999) Extrusion of Aluminum Alloys. Kluwer Academic Publishers, Norwell. http://dx.doi.org/10.1007/978-1-4757-3001-2

[6] ASM Specialty Handbook (2002) Aluminum and Aluminum Alloys, Fabrication and Finishing of Aluminum Alloys. 5th Printing, ASM International, Russell Township. 
Scientific Research Publishing (SCIRP) is one of the largest Open Access journal publishers. It is currently publishing more than 200 open access, online, peer-reviewed journals covering a wide range of academic disciplines. SCIRP serves the worldwide academic communities and contributes to the progress and application of science with its publication.

Other selected journals from SCIRP are listed as below. Submit your manuscript to us via either submit@scirp.org or Online Submission Portal.
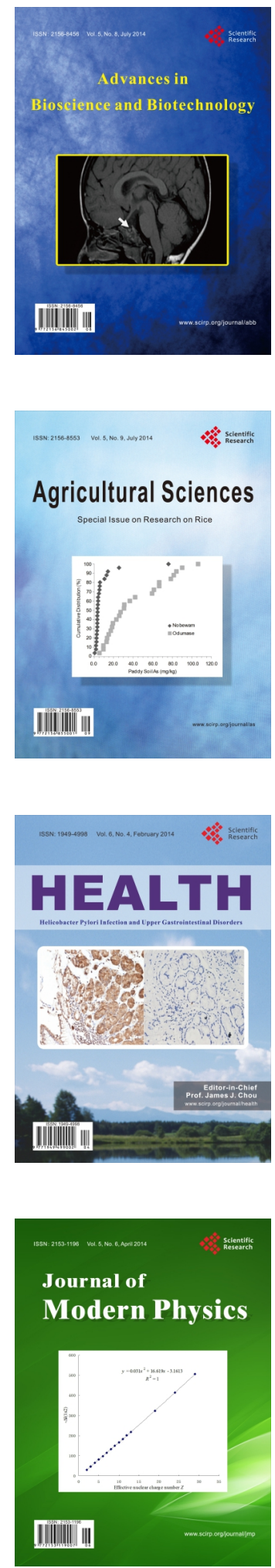
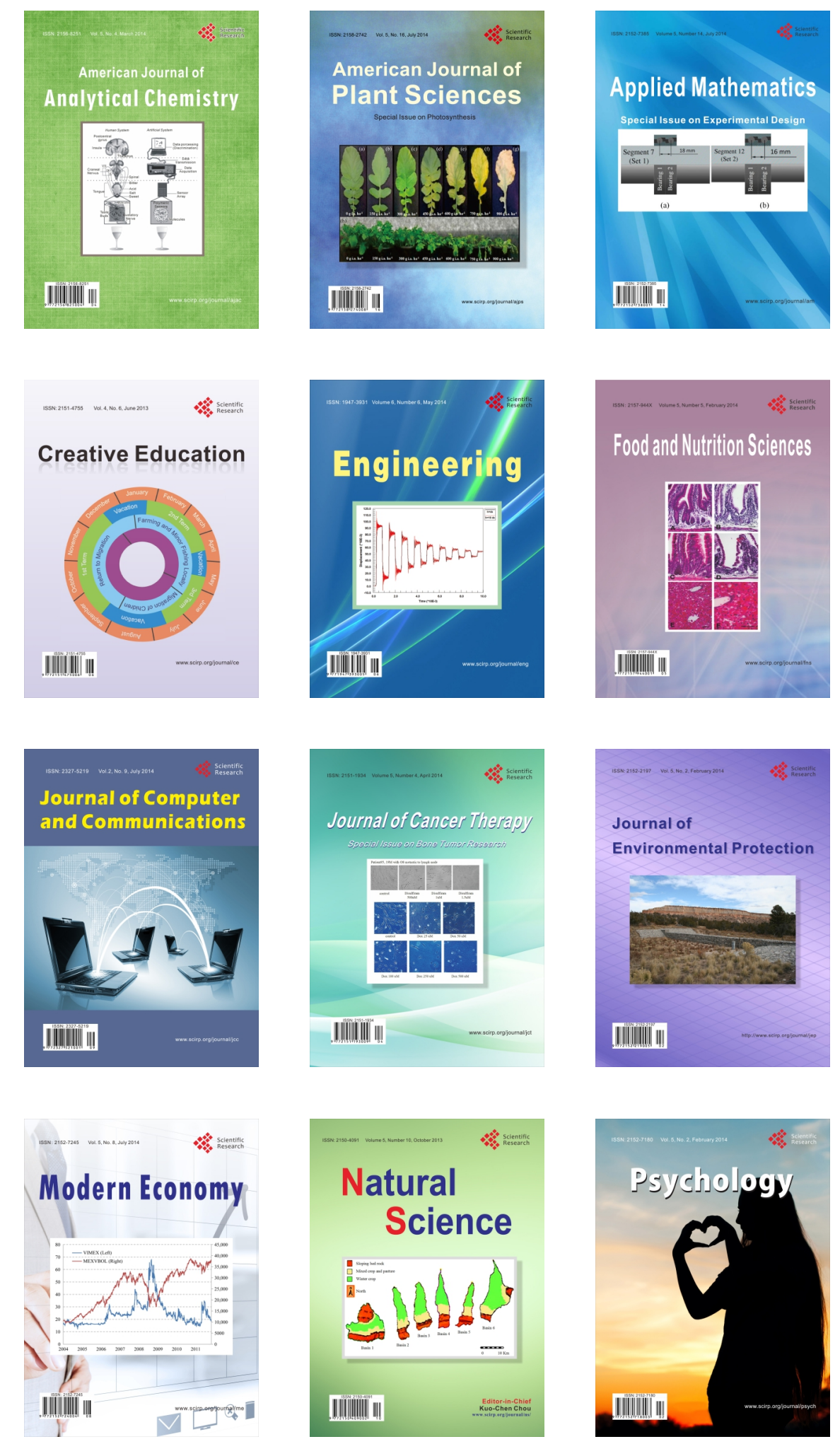